\title{
On the preparation of cyclopentadienes by a novel homolytic annulation of but-3-en-1-ones with alkynes mediated by samarium diiodide
}

\author{
Andrew J. McCarroll and John C. Walton* \\ University of St. Andrews, School of Chemistry, St. Andrews, Fife, UK KY16 9ST \\ E-mail:jcw@st-and.ac.uk
}

Dedicated to Douglas Lloyd on the occasion of his $80^{\text {th }}$ birthday

\begin{abstract}
Treatment of substituted pent-4-en-2-ones and phenylacetylene with samarium diiodide in a mixture of THF and HMPA yielded 3-methyl-1-phenylcyclopent-1-en-3-ols that rapidly dehydrated and underwent [1,5] hydrogen migrations to afford substituted cyclopentadienes. The mechanism involved ketyl radical anions, generated from the unsaturated ketones by $\mathrm{SmI}_{2}$, initially adding to the alkyne. The resulting vinyl type radicals cyclised in the preferred 5-exomode to produce cyclopentenylmethyl radicals that were reduced to the corresponding anions and abstracted a proton from $t-\mathrm{BuOH}$. The overall process amounted to a novel free-radical [3+2]-annulation.
\end{abstract}

Keywords: Cyclopentadienes, novel annulation, hemolytic annulation, but-3-en-1-ones, alkynes, samarium diiodide

\section{Introduction}

The concept of a novel homolytic annulation process, involving unsaturated radicals and alkenes or alkynes, has been turned into a reality by several research groups in the last few years. Essentially, the process is a two-stage cascade consisting of the intermolecular addition of a radical, containing an appropriately placed unsaturated group, to a radical acceptor, followed by intramolecular ring closure of the resulting adduct radical. Most frequently, the initial radical is a but-3-en-1-yl (homoallyl) 1, but-3-yn-1-yl, or analogous species, that adds (A) to a double or triple bond $(\mathrm{A}=\mathrm{B})$ to produce a hex-5-en-1-yl type of radical 2. The latter is well adapted to rapidly cyclise in the allowed 5-exo-mode $\left(\mathbf{C}^{5 \mathbf{x}}\right)$ to produce a cyclopentane derivative 3. 


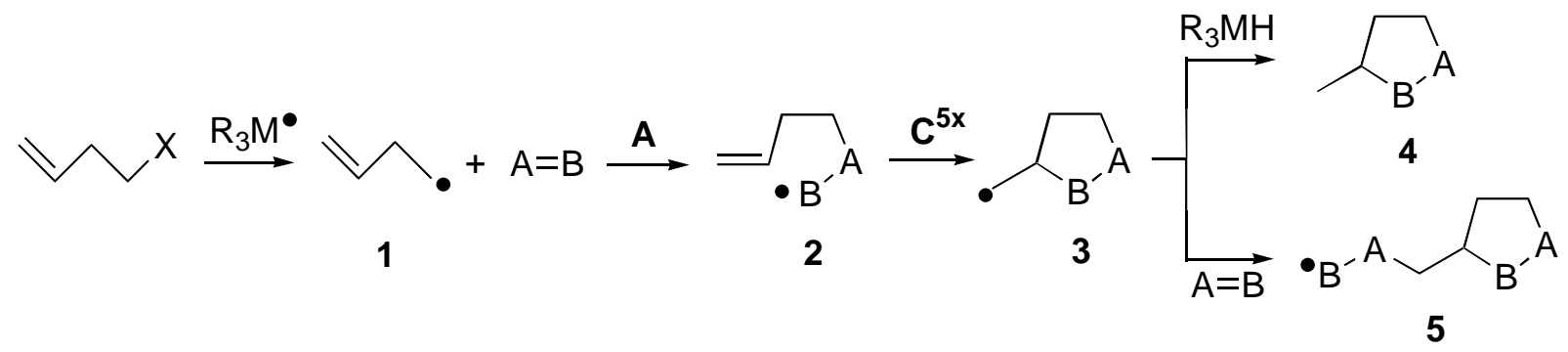

Scheme 1. Archetype free radical annulations and the problem of oligomerisation.

This 2-stage sequence $\left[\mathbf{A C}^{5 \mathrm{x}}\right]$ amounts to a $[3+2]$-annulation ${ }^{1}$ and has obvious potential for the synthesis of cyclopentanes, di- and triquinanes.

Successful homolytic annulation sequences of various types have been reported, ${ }^{2-4}$ but a basic problem with this process is that the cyclised radical $\mathbf{3}$ is rather similar in reactivity to the initial radical 1. Radical 3 may, therefore, add to more acceptor (AB) to produce oligomeric radical 5 , rather than abstract hydrogen from the metal hydride $\left(\mathrm{R}_{3} \mathrm{MH}\right)$ to produce the desired product 4. Ways of circumventing this problem include differentiating the propagating radicals sterically, ${ }^{5,6}$ or electronically, ${ }^{7-10}$ and arranging for the ring closure step to take place onto an aromatic ring. ${ }^{11-13}$

Samarium(II) iodide appeared to be a promising reagent for mediating radical annulations. Reaction of $\mathrm{SmI}_{2}$ with a but-3-en-1-one 6 was expected to generate a ketyl radical anion 7 that should be nucleophilic. Intermolecular addition to a triple bond should, therefore, take place efficiently to generate vinyl radical $\mathbf{8}$ and hence, after a $\mathbf{C}^{5 \mathrm{x}}$ ring closure, cycloalkenylmethyl type radical 9. Radicals 7, 8 and $\mathbf{9}$ are ketyl, vinyl and alkyl types respectively, so these different electronic characters should lead to a sharp difference in reactivity, hence ensuring that oligomerisation is unimportant.

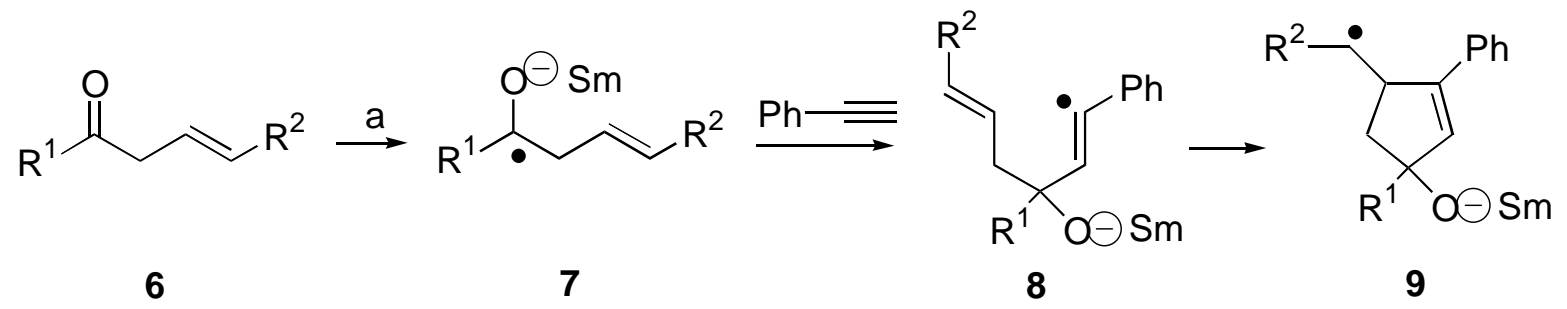

Scheme 2. (a) $\mathrm{SmI}_{2}$, HMPA, $t$-BuOH, THF.

To test the practicality of this annulation sequence a short series of functionalised but-3-en-1ones was prepared and reacted under various sets of conditions. ${ }^{14,15}$ 


\section{Results and Discussion}

The simplest suitable ketone, pent-4-en-2-one 6a was prepared via an organozinc intermediate that underwent addition to a nitrile (Scheme 3). ${ }^{16}$ Work-up proved to be problematic due to the volatility of product, the similar boiling points of starting materials and product and, most seriously, to the instability of the product with respect to the $\alpha, \beta$-unsaturated isomer, pent3 -en-2-one 10a. Repeated careful distillation gave 6a in 39\% yield. Unfortunately, isomerisation to $10 \mathbf{a}$ occurred rapidly, so $\mathbf{6 a}$ had to be prepared immediately prior to use. Hept-1-en-4-one $\mathbf{6 b}$ was made by the same technique, in the hope that purification would be easier. Distillation was again difficult, but the higher boiling point of $\mathbf{6 b}$ compared to $\mathbf{6 a}$ meant that column chromatography could be utilised. Chromatography on silica had previously been avoided because it was suspected that isomerisation would take place on the column. This surmise proved to be unfounded and $\mathbf{6 b}$ was isolated in $40 \%$ yield. Disappointingly, isomerisation to 10b occurred on standing for 24 hours, again necessitating use of $\mathbf{6 b}$ immediately upon preparation.

It was thought that isomerisation might be prevented if an aromatic substituent $\mathrm{R}^{2}$ was introduced. The simple route to 5-phenylpent-4-en-2-one 6c shown in Scheme 3 was chosen. ${ }^{17} \mathrm{~A}$ Knoevenagel condensation yielded 3-styryl-pentane-2,4-dione which was converted to $6 \mathbf{c}$ with of zinc acetate dihydrate in $65 \%$ yield. Gratifyingly, $6 \mathbf{c}$ proved to be stable, and could be kept on the bench indefinitely.
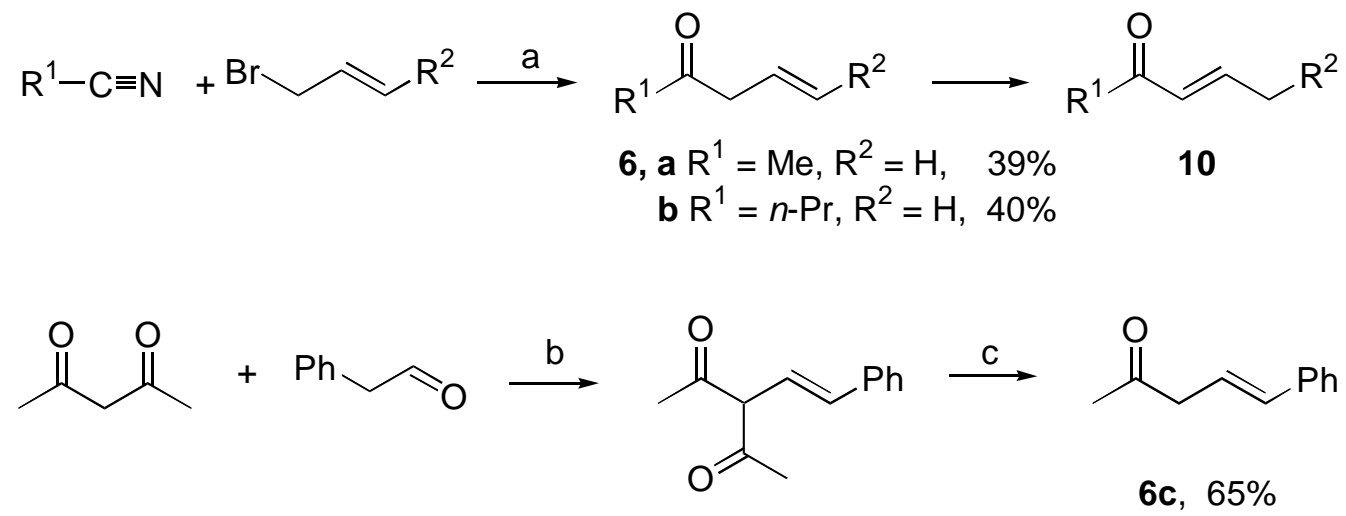

Scheme 3. (a) $\mathrm{Zn} / \mathrm{Ag}, \mathrm{Et}_{2} \mathrm{O}$, THF followed by $\mathrm{H}_{2} \mathrm{O}$. (b) Cat. piperidine (19\%) (c) $\mathrm{Zn}(\mathrm{OAc})_{2} \cdot 2 \mathrm{H}_{2} \mathrm{O}, \mathrm{MeOH}$.

Before attempting any annulations, the addition stage of the process was tested separately by carrying out an intermolecular coupling of phenylacetylene with benzylacetone 11 (Scheme 4). ${ }^{18}$ Samarium(II) iodide was added to phenylacetylene in $t$-butanol and HMPA followed by addition of the benzylacetone. 1,5-Diphenyl-3-methylpent-1-en-3-ol 12 was obtained in 36\% yield, after chromatography. 


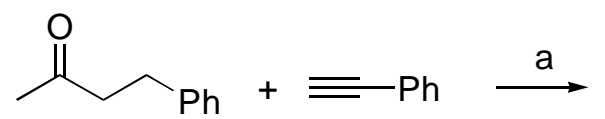

11

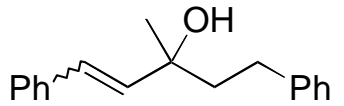

$12,36 \%$

Scheme 4. (a) $\mathrm{SmI}_{2}$, THF, HMPA, $t-\mathrm{BuOH}$.

Subsequently the annulation sequence shown in Scheme 2 above was tested for each of 6a-c. Isolation and purification of the final products was problematic because of the almost identical $\mathrm{R}_{\mathrm{F}}$ values of the product and starting material in whichever solvent system was used. The annulation with 6a was successful, although pure product could not be isolated. NMR spectroscopy indicated that the annulated product 13a had been formed; there was a characteristic singlet at $5.95 \mathrm{ppm}$ in the ${ }^{1} \mathrm{H}$ NMR spectrum, corresponding to an uncoupled alkenyl proton. GC/MS analysis indicated that 13a dehydrated very easily to afford cyclopentadiene 15a. Treatment of $\mathbf{6 b}$ with $\mathrm{SmI}_{2}$ under similar conditions yielded what was believed to be 13b. Addition of this material to deuteriochloroform resulted in the formation of a cloudy emulsion due to the expulsion of water. NMR analysis of the dried material indicated that 13b dehydrated with concomitant thermal rearrangement to give the thermodynamically more stable cyclopentadiene 15b (Scheme 5). Mass spectrometry of the initial material (i.e. product that had not been added to deuteriochloroform) verified this, but indicated that some enol 13b was present, even under the operating conditions of the mass spectrometer. The overall yield was $27 \%$.

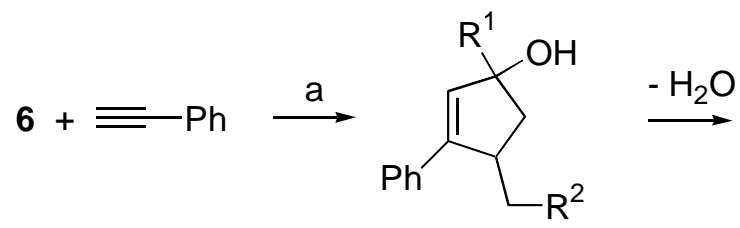

13

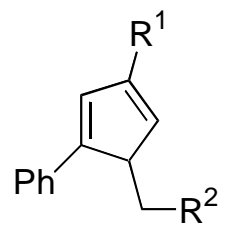

14
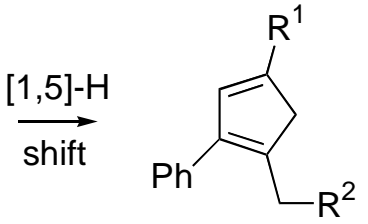

15

Scheme 5. (a) $\mathrm{SmI}_{2}$, THF, MeOH, HMPA.

Use of the more stable precursor enone 6c again led to annulated product. Employment of DMPU as a co-solvent in place of the highly toxic HMPA ${ }^{19,20}$ greatly slowed the reaction. After 3 days of stirring, the reaction mixture was still deep blue. NMR analysis revealed that there was a substantial amount of starting material left in the mixture. Use of HMPA as the co-solvent resulted in complete reaction in under a minute. Unfortunately, purification by repeated column chromatography was not successful, but GC/MS analysis indicated that the annulated product had been formed. It was suspected that loss of product was occurring during column chromatography because cyclopentadienes readily undergo Diels-Alder dimerisation reactions, and it is possible that this was causing the difficulties in separation and low perceived yields. 
Samarium(II) iodide was found to be a suitable mediator of radical annulations. The success of the sequence was due to the difference in reactivity of the propagating radicals. The ketyl radicals generated were highly reactive, and intermolecular addition did not require a large excess of radical acceptor. Oligomerisation did not occur because the final alkyl radical was much less reactive. When the product was a cyclopent-2-enol, as in the examples studied here, dehydration occurred, followed by a concomitant [1,5]-H shift forming a thermodynamically more stable cyclopentadiene derivative. The less than excellent yields were probably a consequence of difficulties encountered in purification, and the dimerisation of the product cyclopentadienes. HMPA was found to be a superior co-solvent to DMPU in the annulation sequences.

\section{Experimental Section}

General Procedures. ${ }^{1} \mathrm{H}$ NMR spectra were obtained using a Bruker AM $300 \mathrm{MHz}$ spectrometer unless otherwise stated, in which case the spectrum was obtained using a Varian Gemini $200 \mathrm{MHz}$ spectrometer. ${ }^{13} \mathrm{C} \mathrm{NMR}$ spectra were run at $75 \mathrm{MHz}$ using the Bruker mentioned above. All samples were dissolved in deuteriochloroform, with tetramethylsilane as an internal standard. Coupling constants are given in Hz. GC/MS analysis was carried out using a Finnigan Incos 50 quadrupole mass spectrometer interfaced with a Hewlett-Packard HP5890 capillary gas chromatograph fitted with a column coated with methylsilicone as the stationary phase. Petroleum ether (PE) refers to the fraction boiling between 40 and $60^{\circ} \mathrm{C}$ unless otherwise stated. Column chromatography was performed using BDH silica gel (40 - $63 \mathrm{~mm})$.

Materials. Were purchased from Aldrich, Avocado or Lancaster. THF and diethyl ether were distilled under nitrogen from sodium benzophenone ketyl prior to use. Samarium diiodide (Aldrich) was a $0.1 \mathrm{M}$ solution in THF. Acetylacetone was distilled prior to use. Other organic compounds were used as received.

Pent-4-en-2-one (6a). ${ }^{16}$ Allyl bromide (32.4 g; $23.2 \mathrm{~mL} ; 0.27 \mathrm{~mol}$ ) was added, over a period of 2.5 hours, to a mixture of acetonitrile $\left(8.2 \mathrm{~g} ; 10.4 \mathrm{~mL}, 0.2 \mathrm{~mol}\right.$ ) and zinc-silver couple ${ }^{17}$ (filings: $18 \mathrm{~g} ; 0.27 \mathrm{~mol})$ in THF $(5 \mathrm{~mL})$ and ether $(45 \mathrm{~mL})$. The mixture was stirred overnight, then poured into a mixture of ether $(100 \mathrm{~mL})$, saturated aqueous ammonium chloride solution $(200 \mathrm{~mL})$ and ice water $(100 \mathrm{~g})$. The mixture was stirred for 10 minutes, then the aqueous layer was separated and extracted with ether. The combined organic layers were dried $\left(\mathrm{MgSO}_{4}\right)$, then the solvents were removed by distillation at room temperature. Careful bulb to bulb distillation $\left(105^{\circ} \mathrm{C} @ 760 \mathrm{mmHg}\right)$ yielded pure pent-4-en-2-one as a colourless oil (6.59 g; 39\%). ${ }^{1} \mathrm{H} \mathrm{NMR} \delta$ $(200 \mathrm{MHz}) 2.17\left(3 \mathrm{H}, \mathrm{s}, \mathrm{CH}_{3}\right), 3.29\left(2 \mathrm{H}, \mathrm{d}, J=6.6, \mathrm{C}(\mathrm{O}) \mathrm{CH}_{2}\right), 5.07-5.23\left(2 \mathrm{H}, \mathrm{m},=\mathrm{CH}_{2}\right), 5.80-$ $6.08(1 \mathrm{H}, \mathrm{m},-\mathrm{CH}=)$.

Hept-1-en-4-one (6b). ${ }^{16}$ Allyl bromide (17.51 g; $12.25 \mathrm{~mL} ; 0.146 \mathrm{~mol}$ ) was added, over a period of 2.5 hours, to a mixture of butyronitrile $(7.46 \mathrm{~g} ; 0.108 \mathrm{~mol})$ and zinc-silver couple (powder: 
$9.46 \mathrm{~g})$ in ether $(27 \mathrm{~mL})$. The mixture was stirred overnight, then poured into a mixture of ether $(100 \mathrm{~mL})$, saturated aqueous ammonium chloride solution $(200 \mathrm{~mL})$ and ice water $(100 \mathrm{~g})$. The mixture was stirred for 10 minutes, then the aqueous layer was separated and extracted with ether $(3 \times 75 \mathrm{~mL})$. The combined organic layers were dried $\left(\mathrm{MgSO}_{4}\right)$ and concentrated at room temperature. Column chromatography (PẼDCM, with contact time of product on silica kept as short as possible) yielded hept-1-en-4-one as a colourless oil (4.82 g; 40\%). ${ }^{1} \mathrm{H}-\mathrm{NMR} \delta 0.92(3 \mathrm{H}$, t, $\left.J=7.4, \mathrm{CH}_{3}\right), 1.60\left(2 \mathrm{H}, \mathrm{m}, \mathrm{CH}_{2} \mathrm{Me}\right), 2.42\left(2 \mathrm{H}, \mathrm{t}, J=7.4, \mathrm{CH}_{2} \mathrm{CH}_{2} \mathrm{CO}\right), 3.16(2 \mathrm{H}, \mathrm{d}, J=6.9$, $\left.\mathrm{COCH}_{2} \mathrm{CH}=\right), 5.11-5.20\left(2 \mathrm{H}, \mathrm{m},=\mathrm{CH}_{2}\right), 5.86-5.98\left(1 \mathrm{H}, \mathrm{m}, \mathrm{CH}=\mathrm{CH}_{2}\right)$.

3-Styrylpentane-2,4-dione. ${ }^{17,21}$ Pentane-2,4-dione (10.01g; $\left.0.1 \mathrm{~mol}\right)$, phenylacetaldehyde $(1.20 \mathrm{~g} ; 0.1 \mathrm{~mol})$ and piperidine $(0.1 \mathrm{~g})$ were stirred for $24 \mathrm{~h}$ at room temperature. DCM $(100 \mathrm{~mL})$ was added, and the mixture was washed with $5 \% \mathrm{HCl}(50 \mathrm{~mL})$ and water $(50 \mathrm{~mL})$, then dried $\left(\mathrm{MgSO}_{4}\right)$, and concentrated. Column chromatograpy (PE/EtOAc) yielded the title compound (3.80 g; 19\%). ${ }^{1} \mathrm{H}-\mathrm{NMR} \delta 1.73\left(6 \mathrm{H}, \mathrm{s}, \mathrm{CH}_{3}\right), 6.42(1 \mathrm{H}, \mathrm{d}, J=16.2, \mathrm{CH}=), 6.75(1 \mathrm{H}, \mathrm{d}$ $J=16.2, \mathrm{CH}=), 7.26-7.45(5 \mathrm{H}, \mathrm{m}, \mathrm{ArH}) .{ }^{13} \mathrm{C}-\mathrm{NMR} \delta 24.3,111.6,123.0,126.3,127.9,128.9$, 134.5, 137.3, 191.5.

1-Phenylpent-1-en-4-one (6c). ${ }^{17}$ 3-Styrylpentane-2,4-dione $(0.80 \mathrm{~g} ; 3.96 \mathrm{mmol})$ and zinc acetate dihydrate $(0.02 \mathrm{~g})$ were refluxed in methanol for 24 hours. Bulb to bulb distillation yielded $\mathbf{6 c}$ $\left(60^{\circ} \mathrm{C} @ 0.04 \mathrm{mmHg}\right)$ as a pale yellow oil $(0.41 \mathrm{~g} ; 65 \%) .{ }^{1} \mathrm{H}-\mathrm{NMR} \delta 2.24\left(3 \mathrm{H}, \mathrm{s}, \mathrm{CH}_{3}\right), 3.35$ $\left(2 \mathrm{H}, \mathrm{d}, \mathrm{CH}_{2}\right), 6.25-6.55(2 \mathrm{H}, \mathrm{m}, \mathrm{CH}=\mathrm{CH}), 7.18-7.45(5 \mathrm{H}, \mathrm{m}, \mathrm{ArH})$.

1,5-Diphenyl-3-methylpent-1-en-3-ol (12). To a flame dried 3-necked flask, purged with nitrogen, was added a solution of samarium(II) iodide in THF $(0.1 \mathrm{M} ; 41 \mathrm{~mL} ; 4.1 \mathrm{mmol})$ followed by phenylacetylene ( $330 \mu \mathrm{l} ; 3 \mathrm{mmol})$, HMPA $(5 \mathrm{~mL}), t$-butanol $(480 \mu \mathrm{l} ; 5 \mathrm{mmol})$, and benzylacetone $(300 \mu \mathrm{l} ; 2 \mathrm{mmol})$. The mixture was decoloured, so more samarium(II) iodide solution was added $(15 \mathrm{~mL} ; 1.5 \mathrm{mmol})$, then the mixture was stirred for 20 minutes. $3 \% \mathrm{HCl}$ was added (50 drops), followed by hexane $(30 \mathrm{~mL})$ and silica gel $(10 \mathrm{~g})$. The mixture was filtered, and the filtrate allowed to stand. An inorganic solid precipitated, and the mixture was filtered again. HMPA was removed by bulb to bulb distillation under vacuum, and the remaining material was purified by column chromatography (hexane/ether 1/1) to give trans-1,5-diphenyl-3-methylpent1-en-3-ol (0.155 g; 28\%) as pure material, and cis-1,5-diphenyl-3-methylpent-1-en-3-ol (0.035 g; $8 \%$ which contained a small amount of benzylacetone impurity. trans-1,5-Diphenyl-3methylpent-1-en-3-ol: ${ }^{1} \mathrm{H}-\mathrm{NMR}(200 \mathrm{MHz}) \delta 1.5\left(3 \mathrm{H}, \mathrm{s}, \mathrm{CH}_{3}\right), 1.60(1 \mathrm{H}, \mathrm{s}, \mathrm{OH}), 1.95(2 \mathrm{H}, \mathrm{m}$, $\left.\mathrm{CH}_{2} \mathrm{CH}_{2} \mathrm{Ph}\right), 2.7\left(2 \mathrm{H}, \mathrm{m}, \mathrm{PhCH}_{2}\right), 6.33(1 \mathrm{H}, \mathrm{d}, J=16.1, \mathrm{HC}=), 6.65(1 \mathrm{H}, \mathrm{d}, J=16.1, \mathrm{HC}=) 7.2-$ 7.5 (10H, m, ArH). ${ }^{13} \mathrm{C}-\mathrm{NMR} \delta 29.1,31.1,45.5,73.8,126.4,127.1,128.1,128.9$ (x 2), 129.0, 136.9, 137.5, 142.9. (Found $\mathrm{M}^{+} 252.1505 . \mathrm{C}_{18} \mathrm{H}_{20} \mathrm{O}$ requires $M$, 252.1514). cis-1,5-Diphenyl-3methylpent-1-en-3-ol: ${ }^{1} \mathrm{H}-\mathrm{NMR} \delta 1.42\left(3 \mathrm{H}, \mathrm{s}, \mathrm{CH}_{3}\right), 1.63(1 \mathrm{H}, \mathrm{bs}, \mathrm{OH}), 1.84-1.96(2 \mathrm{H}, \mathrm{m}$, $\left.\mathrm{CH}_{2} \mathrm{CH}_{2} \mathrm{Ph}\right), 2.80-2.95\left(2 \mathrm{H}, \mathrm{m}, \mathrm{CH}_{2} \mathrm{Ph}\right), 5.75(1 \mathrm{H}, \mathrm{d}, J=12.7, \mathrm{HC}=), 6.60(1 \mathrm{H}, \mathrm{d}, J=12.8$, $\mathrm{HC}=)$, 7.15-7.37 (10H, m, ArH). ${ }^{13} \mathrm{C}-\mathrm{NMR} \delta 30.2,31.1,46.0,75.1,126.2,126.7,127.6,128.7$, $128.8,128.9,129.0,129.3,137.9,138.8,143.0$. 
Samarium(II) iodide mediated annulation of pent-4-en-2-one and phenylacetylene. To a flame dried 3-necked flask, purged with nitrogen, was added a solution of samarium(II) iodide in THF $(0.1 \mathrm{M} ; 41 \mathrm{~mL} ; 4.1 \mathrm{mmol})$ followed by phenylacetylene $(330 \mu \mathrm{l} ; 3 \mathrm{mmol})$, HMPA $(5 \mathrm{~mL}), t-$ butanol (480 $\mu \mathrm{l} ; 5 \mathrm{mmol})$, and pent-4-en-2-one $(300 \mu \mathrm{l} ; 2 \mathrm{mmol})$. The mixture was decoloured, so more samarium(II) iodide solution was added $(15 \mathrm{~mL} ; 1.5 \mathrm{mmol})$, then the mixture was stirred for 20 minutes. $3 \% \mathrm{HCl}$ was added (50 drops), followed by hexane $(30 \mathrm{~mL})$ and silica gel $(10 \mathrm{~g})$. The mixture was filtered, and the filtrate allowed to stand. An inorganic solid precipitated, and the mixture was filtered again. The mixture was partially purified by repeated column chromatography to afford 1,4-dimethyl-3-phenylcyclopent-2-en-1-ol 13a, ${ }^{1} \mathrm{H}-\mathrm{NMR} \delta 1.2(3 \mathrm{H}, \mathrm{d}$, $\left.\mathrm{CH}_{3}\right), 1.5\left(3 \mathrm{H}, \mathrm{s}, \mathrm{CH}_{3}\right), 1.65(\mathrm{bs}, \mathrm{OH}), 2.45(2 \mathrm{H}, \mathrm{m}), 3.45(1 \mathrm{H}, \mathrm{m}), 5.97(1 \mathrm{H}, \mathrm{s}), 7.20-7.50(5 \mathrm{H}$, $\mathrm{m}, \mathrm{ArH}) ;{ }^{13} \mathrm{C}-\mathrm{NMR} \delta 21.1,28.3,37.1,48.7,127.2,128.2,129.3,129.4,149.7$. The mixture was also analysed by GC/MS which showed that dehydration to give (3,5-dimethyl-cyclopenta-1,4dienyl)-benzene 15a occurred very readily, m/z (relative intensity) 170 (68), 155 (100), 128 (50), 115 (46), 91 (68), 77 (61), 51 (53), 39 (63).

Samarium diiodide mediated annulation of hept-1-en-4-one and phenylacetylene: synthesis of 1-methyl-2-phenyl-4-propylcyclopentadiene (15b). To a flame dried 3-necked flask, purged with nitrogen, was added HMPA $(5 \mathrm{~mL}), t$-butanol $(0.56 \mathrm{~g} ; 7.5 \mathrm{mmol})$, phenylacetylene $(0.51 \mathrm{~g}$; $5 \mathrm{mmol})$, and hept-1-en-4-one $(0.34 \mathrm{~g} ; 3 \mathrm{mmol})$ followed by a solution of samarium(II) iodide in THF $(0.1 \mathrm{M} ; 60 \mathrm{~mL} ; 6 \mathrm{mmol})$. The mixture was kept at $-20^{\circ} \mathrm{C}$ overnight, then a saturated aqueous solution of ammonium chloride was added $(50 \mathrm{~mL})$. The mixture was separated, and the aqueous layer extracted with ether $(5 \times 30 \mathrm{~mL})$. The combined organic extracts were washed with water $(50 \mathrm{~mL})$ and brine $(50 \mathrm{~mL})$, then dried $\left(\mathrm{MgSO}_{4}\right)$ and concentrated. The mixture was purified by column chromatography (hexane/ether 3/1). Addition of isolated product to $\mathrm{CDCl}_{3}$ resulted in the formation of water droplets. The solution was dried over $4 \AA$ molecular sieves to give 1-methyl-2-phenyl-4-propylcyclopentadiene $15 \mathrm{~b}(0.22 \mathrm{~g} ; 27 \%)$ as an oil. ${ }^{1} \mathrm{H}-\mathrm{NMR} \delta 0.95$ $\left(3 \mathrm{H}, \mathrm{t}, J=7.3, \mathrm{CH}_{2} \mathrm{Me}\right), 1.59\left(2 \mathrm{H}, \mathrm{m}, \mathrm{MeCH}_{2}\right), 2.11\left(3 \mathrm{H}, \mathrm{s}, \mathrm{CH}_{3}\right), 2.35\left(2 \mathrm{H}, \mathrm{t}, J=7.6, \mathrm{EtCH}_{2}\right)$, $3.00\left(2 \mathrm{H}, \mathrm{s}\right.$, ring $\left.\mathrm{CH}_{2}\right), 6.26(1 \mathrm{H}, \mathrm{s}, \mathrm{CH}=), 7.21-7.39(5 \mathrm{H}, \mathrm{m}, \mathrm{ArH}) .{ }^{13} \mathrm{C}-\mathrm{NMR} \delta 14.1\left(\mathrm{CH}_{3}\right), 14.7$ $\left(\mathrm{CH}_{3}\right), 22.8\left(\mathrm{CH}_{2}\right), 32.9\left(\mathrm{CH}_{2}\right), 49.0\left(\mathrm{CH}_{2}\right), 126.2(\mathrm{CH}), 127.8(\mathrm{CH}), 128.2(\mathrm{CH}), 129.1(\mathrm{CH})$, $135.4,137.3,139.2,146.4$ (all $\mathrm{C}$ ). The product before addition to $\mathrm{CDCl}_{3}$ was analysed by mass spectrometry, but dehydration took place under these conditions to give $\mathbf{1 5 b} \mathrm{m} / \mathrm{z}$ (relative intensity) $198\left(\mathrm{M}^{+}\right)(39), 183$ (22), 173 (100), 169 (39), 155 (10), 141 (10), 129 (9), 128 (10) 115 (10), 91 (16). (Found: $\mathrm{M}^{+}$198.1401. $\mathrm{C}_{15} \mathrm{H}_{18}$ requires $\left.M, 198.1409\right)$. A small amount, ca. $1 \%$, of 13b was still present as indicated by the spectra.

Samarium diiodide mediated annulation of 1-phenylpent-1-en-4-one and phenylacetylene. To a flame dried 3-necked flask, purged with nitrogen, was added a solution of samarium(II) iodide in THF $(0.1 \mathrm{M} ; 50 \mathrm{~mL} ; 5.0 \mathrm{mmol})$ followed by phenylacetylene $(330 \mu \mathrm{l} ; 3 \mathrm{mmol})$, DMPU ( $5 \mathrm{~mL}$ ), t-butanol (480 $\mu \mathrm{l} ; 5 \mathrm{mmol})$, and 1-phenylpent-1-en-4-one (0.32 g; $2 \mathrm{mmol})$. The mixture was stirred for 3 days under nitrogen, after which the mixture was still deep blue, then a saturated aqueous solution of sodium hydrogen carbonate was added $(50 \mathrm{~mL})$, and the mixture extracted with ether $(3 \times 30 \mathrm{~mL})$, dried $\left(\mathrm{MgSO}_{4}\right)$ and concentrated. NMR and GC/MS analysis indicated that there was still a substantial amount of 1-phenylpent-1-en-4-one present. Repeated 
column chromatography (hexane/ether and hexane/ethyl acetate) failed to isolate pure annulated product, but GC/MS indicated that 15c had been formed (ca. $30 \%$ ), m/z (relative intensity) 246 $\left(\mathrm{M}^{+}, 100\right), 160$ (45), 155 (95), 145 (56), 117 (93), 115 (59), 91 (64), 43 (44). (Found: $\mathrm{M}^{+}$ 246.1402. $\mathrm{C}_{19} \mathrm{H}_{18}$ requires $\left.M, 246.1409\right)$. The reaction was repeated as above using HMPA instead of DMPU as co-solvent. The reaction was complete in under a minute, and no 1phenylpent-1-en-4-one remained in the reaction mixture.

\section{Acknowledgements}

We thank the EPSRC for financial support

\section{References and Notes}

1. See: McCarroll, A. J.; Walton, J. C. Angew. Chem., Int. Ed. 2001, 40, 2225 for a description of this cascade classification system.

2. Angoh, A. G.; Clive, D. L. J. J. Chem. Soc., Chem. Commun. 1985, 980.

3. Saičić, R. N.; Čeković, Ž. Tetrahedron 1990, 46, 3627.

4. Barton, D. H. R.; da Silva, E.; Zard, S. Z. J. Chem. Soc., Chem. Commun. 1988, 282.

5. Giese, B. Angew. Chem., Int. Ed. 1983, 22, 753.

6. San Miguel, B. A.; Maillard, B.; Delmond, B. Tetrahedron Lett. 1987, 28, 2127.

7. Srikrishna, A.; Hemamalini, P.; Venkateswarlu, S. Tetrahedron 1994, 50, 8781.

8. Curran, D. P.; Seong, C. M. Tetrahedron 1992, 48, 2157, 2175.

9. Snider, B. B. Chem. Rev. 1996, 96, 339.

10. Boiteau, L.; Boivin, J.; Liard, A.; Quiclet-Sire, B.; Zard, S. Z. Angew. Chem., Int. Ed. 1998, 38, 1128.

11. Snider, B. B.; Buckman, B. O. Tetrahedron 1989, 45, 6969.

12. Santi, R.; Bergamini, F.; Citterio, A.; Sebastiano, R.; Nicolini, M. J. Org. Chem. 1992, 57, 4250 .

13. Miranda, L. D.; Cruz-Almanza, R.; Pavón, M.; Romero, Y.; Muchowski, J. M. Tetrahedron Lett. 2000, 41, 10181.

14. Molander G. A.; Harris, C. R. Tetrahedron 1998, 54, 3321.

15. Molander G. A.; Harris, C. R. Chem. Rev. 1996, 96, 307.

16. Rousseau G.; Conia, J. M. Tetrahedron Lett. 1981, 22, 653.

17. Uehara, K.; Kitamura, F.; Tanaka, M. Bull. Chem. Soc. Jpn. 1976, 49, 496.

18. Inanaga, J.; Katsuki, J.; Ujikawa, O.; Yamaguchi, M. Tetrahedron Lett. 1991, 32, 4921.

19. Mukhopadhyay, T.; Seebach, D. Helv. Chim. Acta 1982, 65, 385.

20. Molander, G. A.; McKie, J. A. J. Org. Chem. 1992, 57, 3132.

21. Verhé, R.; de Kimpe, N.; Courtheyn, D.; de Buyck, L.; Schamp, N. Tetrahedron 1982, 38, 3649. 